\title{
Thymus vulgaris extract modulates dexamethasone induced liver injury and restores the hepatic antioxidant redox system
}

\author{
Howida Sayed Abou-Seif ${ }^{* *}$ (D), Walaa Gamal Hozayen ${ }^{2,3}$ and Khalid Shaaban Hashem ${ }^{4}$
}

\begin{abstract}
Background: The liver is the largest important organ and the site for essential biochemical reactions and detoxifying toxic substances in the human body. Long-term, high-dose dexamethasone administration can cause severe alterations in liver function. Therefore, Thymus vulgaris leave extract possess a modulatory role on dexamethasone-induced hepatotoxicity by attenuating antioxidant defense system.

By subcutaneous route, animals will receive three doses per week for 8 weeks of dexamethasone $(0.1 \mathrm{mg} / \mathrm{kg}$. b. wt.) concomitant with oral administration of thyme aqueous extract (500 mg/kg b.wt.).

Results: DXM treatment led to a marked increase in the liver function enzyme activities that are successfully ameliorated by thyme aqueous extract. Thyme natural antioxidants augmented the antioxidant defense system that overcomes oxidative stress caused by dexamethasone. Conversely, although dexamethasone-treated animals rose lipid peroxidation, thyme extract pretreatment did the reverse.
\end{abstract}

Conclusion: Hepatotoxicity and oxidative stress caused by dexamethasone might improve by thyme natural antioxidants.

Keywords: Dexamethasone, Liver enzymes, Natural antioxidants, Oxidative stress

\section{Background}

The liver is the main site for powerful metabolism and elimination of chemicals, foreign substances, drugs, and toxic mixtures. Damage in the hepatic tissue accompanied by elevated tissue malonaldialdehyde, cellular necrosis, and reduced glutathione levels was diminished. Also, serum levels of cholesterol, bilirubin, transaminases, triglycerides, and alkaline phosphatase are raised in hepatic disease [4, 42]. Suprarenal medullary gland secretes glucocorticosteroids (GCs) or steroid hormones that have immunomodulation and regulating metabolism actions [7]. The ingestion of dexamethasone overdose wastes its effect as a longacting anti-inflammatory synthetic steroid [29]. Synthetic and natural glucocorticoids are considered as a leader of the anti-inflammatory and immunosuppressive treatments.

\footnotetext{
* Correspondence: drhoidaabouseif@gmail.com

${ }^{1}$ Medical Physiology Department, Medical Research Branch, The National

Research Centre, Dokki Cairo, Egypt

Full list of author information is available at the end of the article
}

Acute and chronic inflammations as multiple sclerosis, eczema, and rheumatoid arthritis are widely treated with glucocorticoids. Furthermore, organ transplant, immunosuppressive regimes, and leukemia are also using glucocorticoids. Long-term use of oral glucocorticoids may lead to metabolic disease, osteoporosis, and cardiovascular disorder ([46] [44];). Long-term treatment of dexamethasone had several side effects, for example, initiation of the free radicals which might play a role in oxidative stress, skeletal muscle atrophy, and insulin resistance, although it is effective in immunosuppression and anti-inflammatory properties $[15,47]$. Dexamethasone induced hepatic injury through excessive formation of free radical which caused oxidative stress [23].

Dietary natural antioxidant compounds have pay attention to its ameliorative effects, which are found in fruits, vegetables, and seeds. Also in traditional and alternative medicine, dietary antioxidant is considered as a treatment [24]. Thymus species are rich sources of secondary 
metabolites that play key roles in delaying the development of diseases such as cancer and chronic inflammation. Metabolites have notable radical scavenging and antimicrobial properties as the phenolic monoterpenoids, thymol, and carvacrol [43]. Also, flavonoids such as luteolin and apigenin derivatives and phenolic acids such as rosmarinic acids, cinnamic, and carnosic give an important contribution to the antioxidant capacity of thyme extracts [13]. In several experimental models of liver injury, several species of plant, for example, thyme, contain other metabolites, i.e., chemotypes (chemical phenotypes), cause hepatoprotective effects. Liver injury in rats induced by carbon tetrachloride $(\mathrm{CCl} 4)$ could ameliorate by thyme extract and essential oil $[1,5]$. The defensive effects of thyme essential oil and watery extract are found, versus paracetamol, cause hepatic damage. Plant secondary metabolites are natural products that were examined to be a recent source of therapeutic and pharmaceutical agents which characterized definitive plants. The entire body is affected by the liver, which is considered as the center of biochemical transformations. Particularly, the liver is susceptible to sudden increases in reactive oxygen species (ROS) levels plus further prooxidants as the center of detoxification and synthesis of a number of essential substances [17, 21]. The central role that controlled ROS concentrations is played by an enzyme (superoxide dismutase), which synthesizes hydrogen peroxide plus degraded by glutathione-dependent peroxidase or catalase into oxygen and water, although ROS (reactive oxygen species) concentrations are controlled by specialized metabolic pathways [38, 49]. Glutathione Stransferase (GST) supplemented this first line of antioxidant defense, which conjugates reactive electrophilic compounds with glutathione and initiates their detoxification [16]. Regarding the increasing oxidative stress and antioxidant defense of herbs, the current research is conducted to assess the protective role of thyme watery extract on DXMenhanced hepatotoxicity in albino rats.

\section{Methods}

\subsection{Animal preparation}

In the current investigation, 120-150 g (female) albino rats were used. The rats were obtained from Ophthalmology Research Center animal house in Giza, Egypt, according to the [12]. Two weeks ahead the beginning of the study, the animals were housed under examination to prevent any intercurrent infection. Rats were exposed to natural conditions (daily light-dark cycles and kept at room temperature). Clean water always existed and they were fed ad libitum.

\subsection{Chemicals}

By Sigma-Tec (Merck, Darmstadt, Germany, permission), DXM (Fortecortin ${ }^{\odot} 8 \mathrm{mg}$-mono ampoule) is manufactured in Egypt-S. A. E by medicinal manufactures.

\subsection{Herbal preparation}

For medicinal plants (Cairo, Egypt), T. vulgaris L. (Lamiaceae) leaves were bought from Sekem Co. An ecologist identified $T$. vulgaris leaves and a labeled sample was present in Beni-Suef University, Faculty of Science, Botany Department, Egypt.

\subsection{Water extract of Thymus vulgaris}

Aerial material of dried thyme [40] weighing 30 grams was infused in distilled water $(60 \mathrm{~mL})$ for a day. By using filter paper, sample was filtered and the filtrate was kept at $-20{ }^{\circ} \mathrm{C}$ just for 3 days.

\subsection{Drug administration}

In the current finding, $0.1 \mathrm{mg} / \mathrm{kg}$ b.wt. of DXM dosage was used. Feng et al. [18] reported that this dose, previously, increased in the frequency of hepatotoxicity and ovarian toxicity in mammalian systems. Rats were injected three times per week with $0.1 \mathrm{mg} / \mathrm{kg}$ b.wt. of DXM (adjusted in sterile water proceeding to use) subcutaneously concomitant with $500 \mathrm{mg} / \mathrm{kg}$ b.wt. of TAE (thyme aqueous extract) for 8 weeks [40].

\subsection{Experimental design}

Thirty animals were distributed to:

1. G1 (Group 1) normal or negative control: daily for 8 weeks, animals were provided with distilled water.

2. G2 (Group 2) toxic group: animals were injected by subcutaneous route three times a week for 8 weeks with $0.1 \mathrm{mg} / \mathrm{kg}$ b. wt. of DXM.

3. G3 (Group 3) thyme- and DXM-treated group: rats were injected subcutaneously three times per week with $0.1 \mathrm{mg} / \mathrm{kg}$ b.wt. of DXM concomitant with oral administration of $500 \mathrm{mg} / \mathrm{kg}$ b. wt. of TAE for 8 weeks [40].

\subsection{Sampling}

Rats were sacrificed (in the morning) by cervical decapitation and a 5-mL blood sample was collected in a centrifuge tube from the jugular vein of each animal under light ether anesthesia [9]. At room temperature for 45 min, the blood sample was left to clot. For various physiological and biochemical analyses at $3000 \mathrm{rpm}$, the clear sera were separated for $15 \mathrm{~min}$ at $30{ }^{\circ} \mathrm{C}$ by centrifugation and kept frozen at $-20{ }^{\circ} \mathrm{C}$.

\subsection{Biochemical analyses}

The serum samples were used to estimate serum alkaline phosphatase (ALP) activity kinetically $[11,36]$ method was used to determine LDH (lactate dehydrogenase) using Stanbio Laboratories reagent kit purchased from Texas, USA. Biodiagnostic kits were used to estimate ALT plus 
AST (alanine aminotransferase and aspartate aminotransferase) activities [35].

\subsection{Hepatic oxidative stress and antioxidant enzymes analyses}

The liver was removed rapidly after dissection and homogenized $0.5 \mathrm{~g}$ in $5-\mathrm{mL}$ normal saline solution $(0.9 \%$ $\mathrm{NaCl}$ " $10 \% \mathrm{w} / \mathrm{v}$ ") by Teflon homogenizer. Liver clear supernatants used to measure the activity of catalase (CAT) were assayed following the method of Aebi [3]. Beutler et al. [10] method was used to measure glutathione (GSH), Ohkawa et al. [32] used to estimate lipid peroxidation (LP), and glutathione S-transferase (GST) and glutathione peroxidase (GSP) activities were estimated by the method of Habig et al. [22] and Paglia and Valentine [34] respectively. Glutathione reductase (GSR) activity was done using Goldberg and Spooner [20] method.

\subsection{Histopathological study}

Liver samples from each group washing with normal saline were fixed in $10 \%$ buffered formalin, inserted in paraffin wax, dehydrated and exposed to H\& E (hematoxylin and eosin), then sectioned into 5- $\mu \mathrm{m}$ thickness according to the method of Banchroft et al. [8] to compare their morphologies.

\subsection{Statistical analysis}

Data are expressed as mean \pm SEM for post hoc analysis, and one-way variance analysis was used to establish statistical differences followed by TukeyKramer methods. Data done by ANOVA (one-way analysis of variance) were used, were presented as mean \pm SEM, and were analyzed. When $P<0.05$, statistically significant data was considered by using GraphPad Prism 5 software for statistical analysis (San Diego, CA, USA).

\section{Results}

\subsection{Biochemical changes}

Variations in various serum parameters associated with liver function are shown in Table 1 and Figs. 1, 2, 3, and 4. Regarding liver function enzymes interrelated, the dexamethasone-managed group showed important surge of ALP, AST, ALT, and LDH activities. Thyme aqueous extract management effectively enhanced theses elevated enzymes.

The liver antioxidant defense system is shown in Table 2 and Figs. 5, 6, 7, 8, 9 and 10. Animals treated with thyme caused a great elevation of the liver glutathione level that was markedly increased; the proportion was 89.02\% as competed with DXM-treated animals (44.76), which revealed important reduction in reduced glutathione level paralleled to non-treated animals. Liver CAT, GSP, GST, and GSR activities demonstrated a marked significant rise in TAE-treated group that corresponds to DXM group which reduced significantly. Dissimilarity, liver LP was elevated significantly as a result of DXM management, although the TAE produced a significant reduction of the elevated value.

\subsection{Histopathological changes}

Figure 11a shows the microscopic hepatic examination in normal control group without pathological alteration. Conversely, hepatic cell degeneration, vacuolation, and pyknotic nuclei were produced in DXM-treated rats (Fig. 11b), whereas thyme pretreated group (Fig. 11c) showed normal hepatocytes with very little vacuolation.

\section{Discussion}

In the existing results, dexamethasone induced liver injury by increasing AST, ALT, ALP, and LDH activities. However, TAE management effectively enhanced the elevated enzyme activities of the above-mentioned parameters. These investigations are in agreement with other studies $[23,42]$ which declared that any harm in the liver can weaken its functions and cause numerous implications on human health as it is the chief site of

Table 1 The defensive role of thyme aqueous extract on serum alkaline phosphatase (ALP), aspartate aminotransferase (AST), alanine aminotransferase (ALT), and lactate dehydrogenase (LDH) activities in normal and dexamethasone (DXM) treated rats

\begin{tabular}{|c|c|c|c|c|c|c|c|c|}
\hline \multicolumn{9}{|l|}{ Treatments } \\
\hline Parameters & $\begin{array}{l}\text { Serum ALP } \\
(\mathrm{lu} / \mathrm{l})\end{array}$ & \% change & $\begin{array}{l}\text { Serum AST } \\
(\mathrm{lu} / \mathrm{l})\end{array}$ & $\%$ change & Serum ALT (lu/I) & \% change & $\begin{array}{l}\text { Serum LDH } \\
(\mathrm{lu} / \mathrm{l})\end{array}$ & $\%$ change \\
\hline $\begin{array}{l}\text { G1 } \\
\text { Normal }\end{array}$ & $183.0 \pm 3.59$ & - & $173.7 \pm 2.18$ & - & $55.88 \pm 1.43$ & - & $2481 \pm 16.4$ & - \\
\hline $\begin{array}{l}\text { G2 } \\
\text { Dexamethasone }\end{array}$ & $303.0 \pm 3.49^{* * *}$ & 65.57 & $264.0 \pm 5.45^{* * *}$ & 51.99 & $77.88 \pm 3.24$ & 39.37 & $2680 \pm 20.17^{* * *}$ & 4.37 \\
\hline $\begin{array}{l}\text { G3 } \\
\text { Thyme }\end{array}$ & $247.7 \pm 5.10^{* * *}$ & -18.25 & $179.8 \pm 1.99^{* * * *}$ & -31.89 & $56.35 \pm 1.28^{* * *}$ & -38.21 & $2563 \pm 21.72^{* * *}$ & 8.02 \\
\hline F-Probability & $P<0.6447$ & - & $P<0.0001$ & - & $P<0.0001$ & - & $P<0.0002$ & - \\
\hline
\end{tabular}

Data are expressed as mean \pm standard error. Number of animals in each group is ten. Mean, which have the same superscript symbol(s), are not significantly different. Percentage changes (\%) were calculated by comparing normal group with DXM-treated group and pre-treated DXM groups with DXM-treated group 


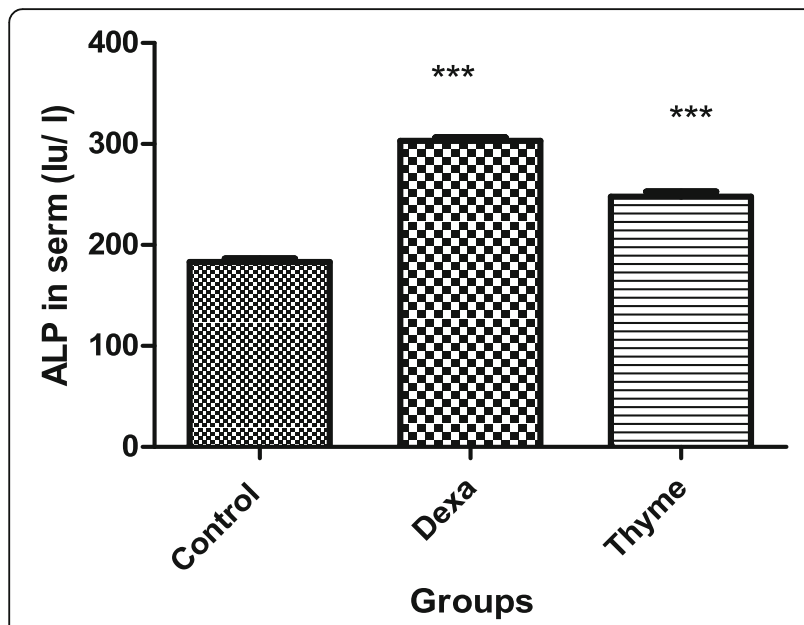

Fig. 1 The defensive role of thyme aqueous extract on serum alkaline phosphatase activity in normal and dexamethasone (DXM)-treated rats. Percentage changes (\%) were calculated by comparing normal group with DXM-treated group and pre-treated DXM groups with DXM-treated group

intense metabolism and excretion and plays an essential task in excretion plus detoxification of several exogenous beside endogenous components, and hepatic damage resulted from the distortion of these metabolic functions. Corticosteroid therapy associated with liver injuries leads to elevated liver function enzymes. Hydroxyl radicals plus superoxide anions enhanced inflammatory cell infiltration in the portal area, accompanied by liver injury, may be attributed to DXM which induces cell membrane oxidative damage leading to fatty liver change [26].

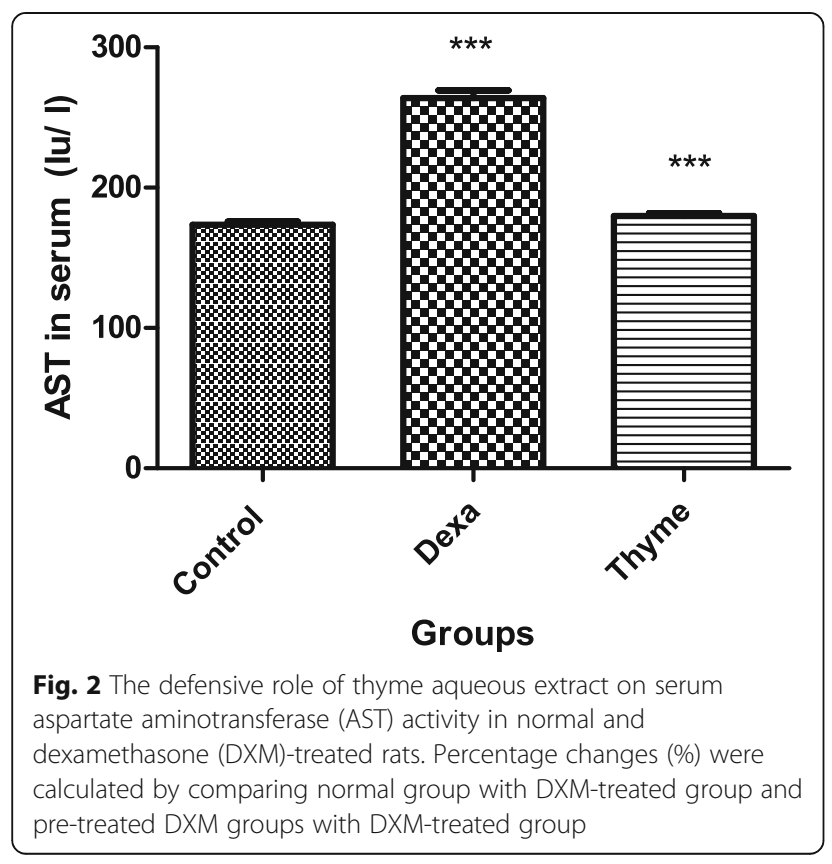

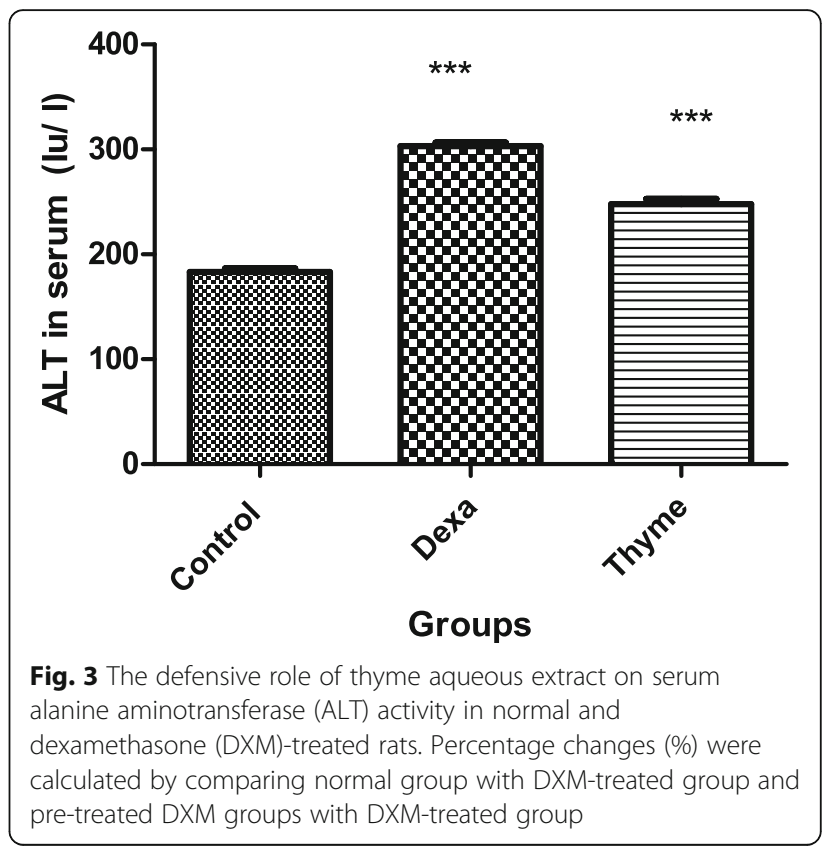

The histopathological alterations induced by DXM in the existing study agree with Safaei et al. [37] who revealed that dexamethasone caused necrosis, infiltration in the inflamed tissue, and severe hepatocyte erosion. Dexamethasone declines hepatocyte proliferation activity and, accordingly, their regeneration capacity [31]. High doses of glucocorticoids, especially dexamethasone, suppress the expression of hepatocyte growth factor due to declined proliferation capacity. The liver cell morphological alterations were associated with sinusoid plus central vein dilatation [27]. Dexamethasone elevated the

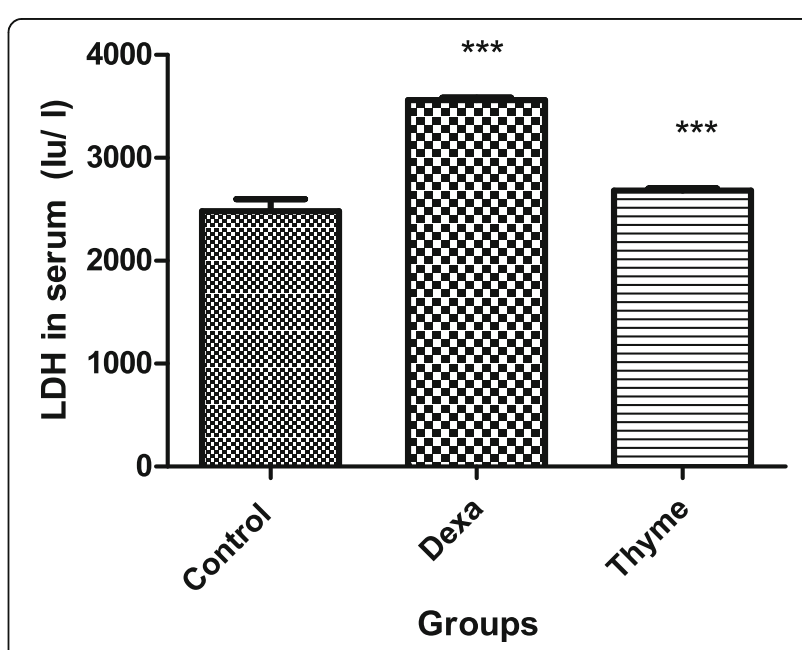

Fig. 4 The defensive role of thyme aqueous extract on serum lactate dehydrogenase (LDH) activity in normal and dexamethasone (DXM)-treated rats. Percentage changes (\%) were calculated by comparing normal group with DXM-treated group and pre-treated DXM groups with DXM-treated group 


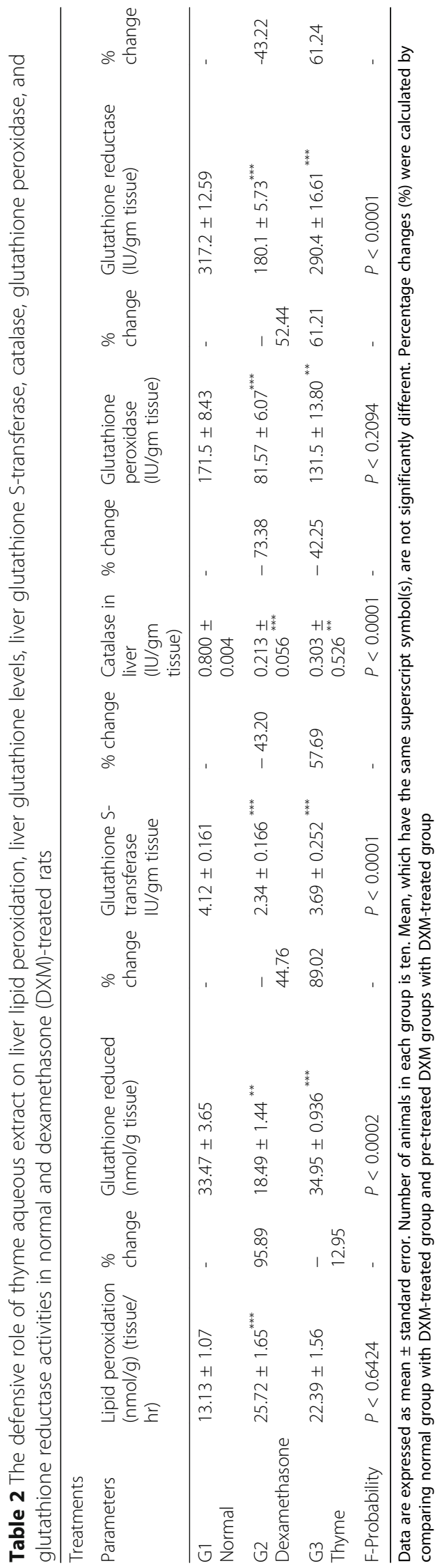




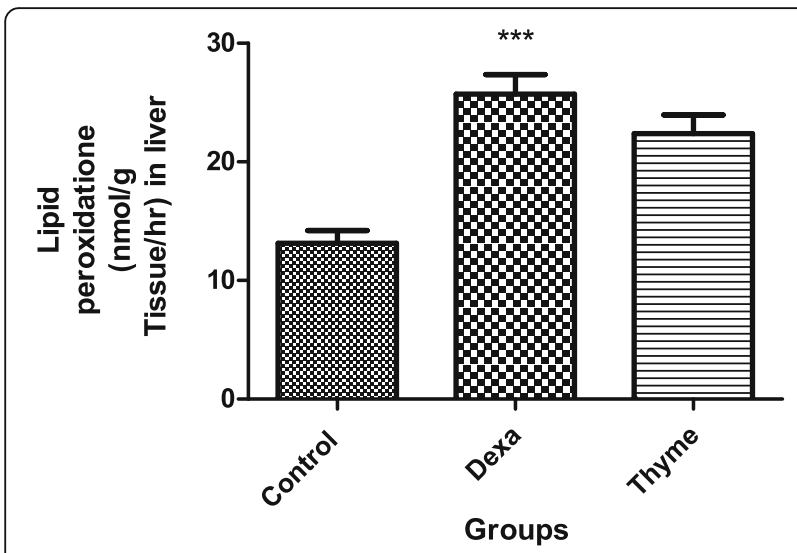

Fig. 5 The defensive role of thyme aqueous extract on liver lipid peroxidation level in normal and dexamethasone (DXM)-treated rats. Percentage changes (\%) were calculated by comparing normal group with DXM-treated group and pre-treated DXM groups with DXM-treated group

osmotic pressure, disturbing electrolyte balance and affects the sodium-potassium pump in the liver cells due to cell vacuolization and blebbing [2].

Regarding the oxidative stress, the existing findings agreed with [24] who have indicated that the major cause of liver injury induced by dexamethasone is oxidative stress that is produced from the extreme formation of free radicals. Elevated amounts of dexamethasone markedly reduced the actions of whole antioxidant capacity in addition to superoxide dismutase, resulting in oxidative stress by increasing the volumes of peroxide hydrogen plus malondialdehyde [30]. Herbs may have a variety of phytochemicals that differ from phenolic complexes for antioxidant and bitter complexes which stimulate the digestive system beside several other

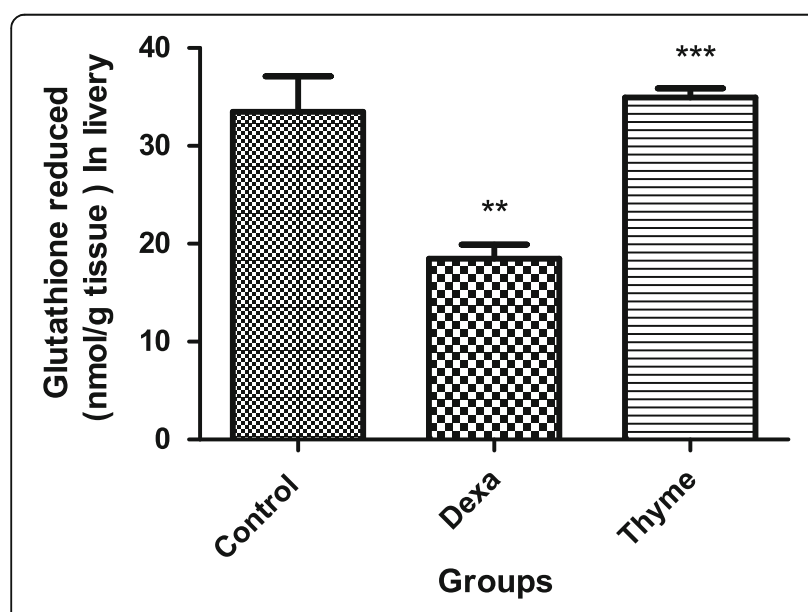

Fig. 6 The defensive role of thyme aqueous extract on liver glutathione level in normal and dexamethasone (DXM)-treated rats. Percentage changes (\%) were calculated by comparing normal group with DXMtreated group and pre-treated DXM groups with DXM-treated group

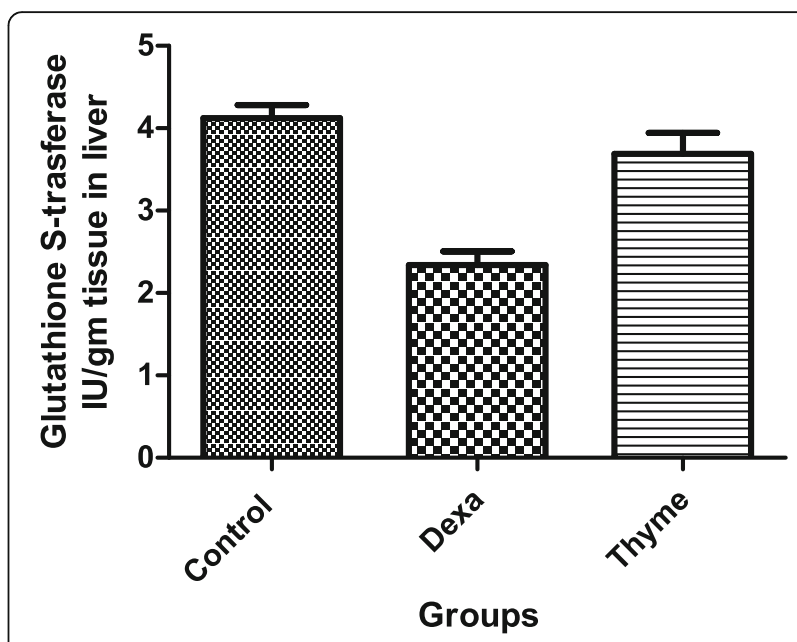

Fig. 7 The defensive role of thyme aqueous extract on liver glutathione S-transferase activity in normal and dexamethasone (DXM)-treated rats. Percentage changes (\%) were calculated by comparing normal group with DXM-treated group and pre-treated DXM groups with DXM-treated group

pharmacological characteristics including antifungal and antibacterial effects [14].

Oxidative stress returns an inequality among the capabilities of the biological systems to fix the damage or to quickly detoxify the reactive intermediates and the reactive oxygen species' systemic expression. The formation of free radical plus peroxides from redox state disturbance of the cell leads to damage of all cell components including breaking the DNA strand and base damage [6]. ROS generated indirectly and mostly from base damage, for example hydroxyl radical and superoxide radical "hydrogen peroxide." Proteins, lipids, and DNA are the main cellular components affected through oxidative stress. Oxidative

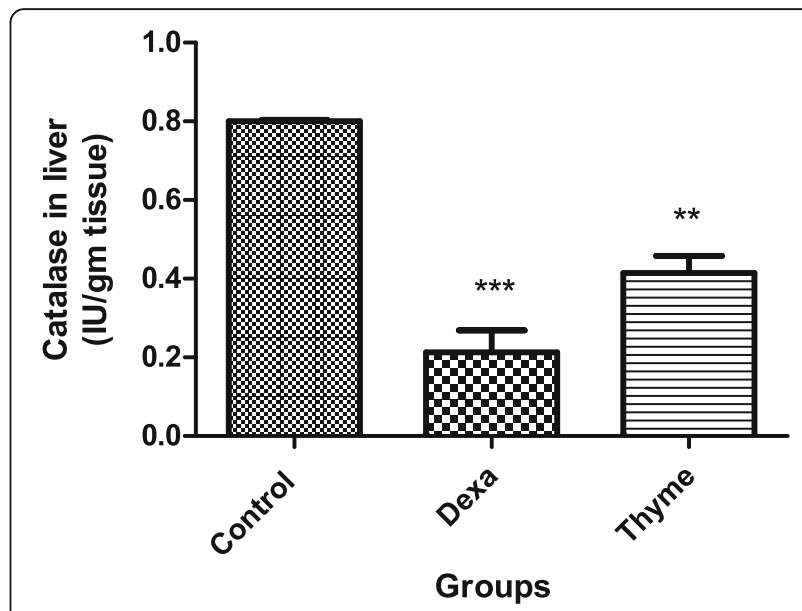

Fig. 8 The defensive role of thyme aqueous extract on liver catalase activity in normal and dexamethasone (DXM)-treated rats. Percentage changes (\%) were calculated by comparing normal group with DXMtreated group and pre-treated DXM groups with DXM-treated group 


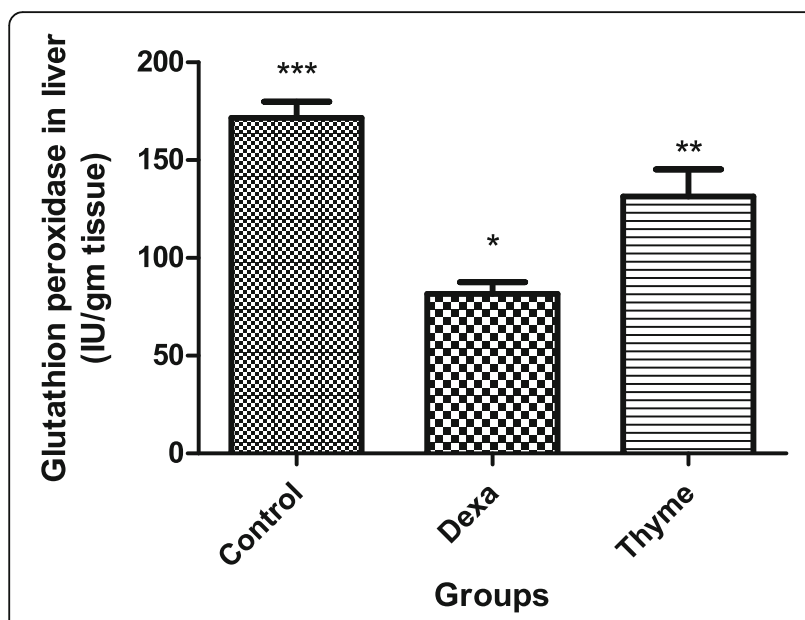

Fig. 9 The defensive role of thyme aqueous extract on liver glutathione peroxidase activity in normal and dexamethasone (DXM)-treated rats.

Percentage changes (\%) were calculated by comparing normal group with DXM-treated group and pre-treated DXM groups with DXM-treated group.

stress has significant role in numerous pathogenesis of degenerative diseases like cancer, diabetes, cardiovascular disorders, or neurodegenerative diseases [41]. So, balance between oxidant and antioxidant particles produced the complex task of oxidant progression in cells. Several enzymes performed protective actions against ROS, for example, glutathione peroxidase, superoxide dismutase (SOD), and catalase, in addition to non-enzymatic components as glutathione, vitamin E tocopherol, beta-carotene, and ascorbate. Reduction in the capacity of this antioxidant system raises inactivated ROS level, enzymatic or non-enzymatic reactions activated ROS formation, and ROS generation altered transition potential and mitochondrial permeability $[28,45]$. Pro-apoptotic factors

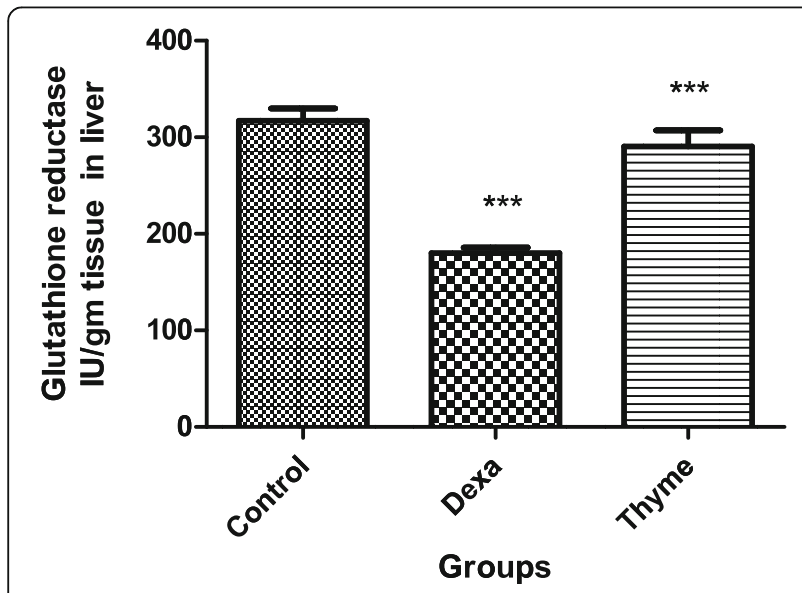

Fig. 10 The defensive role of thyme aqueous extract on liver glutathione reductase activity in normal and dexamethasone (DXM)treated rats. Percentage changes (\%) were calculated by comparing normal group with DXM-treated group and pre-treated DXM groups with DXM-treated group

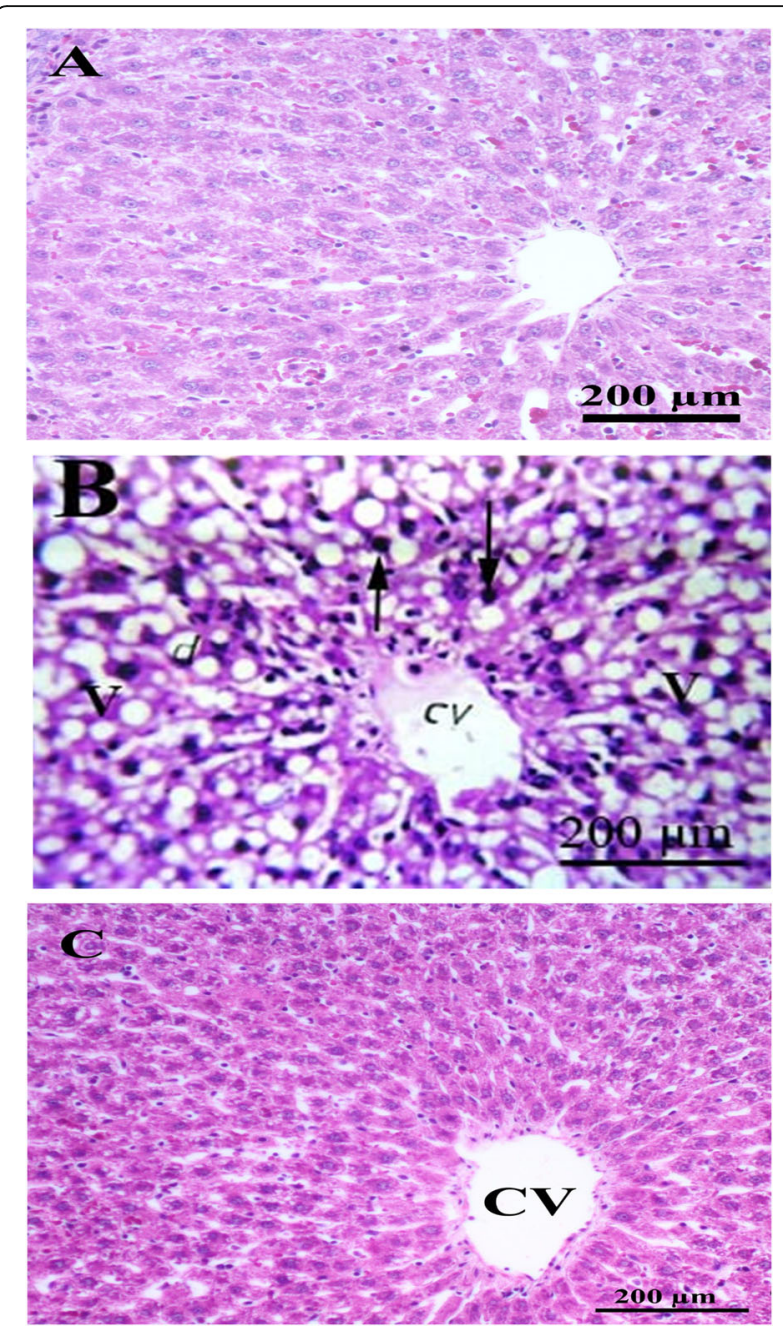

Fig. 11 a A transverse section of a liver of normal control (distilled water) rat showing a central vein, hepatic cords, and sinusoids in between, $\times 400$. $\mathbf{b}$ A transverse section of a liver of dexamethasone group showing degenerative changes $(d)$, vacuolation $(V)$ all over the hepatocytes and pyknotic nuclei $(\uparrow), \times 400$. c A transverse section of a liver of dexamethasone and thyme group showing normal central vein $(\mathrm{CV})$, hepatocytes with very little cell vacuolation, $\times 400$

(cytochrome C) were initiated according to these variations. Moreover, oxidative stress may induce changes (reversible and irreversible) in sensitive proteins that are concomitant frequently with neurodegenerative disturbances [33, 48]. Lipid hydroperoxides resulted from cholesterol glycolipids, cholesterol esters, phospholipids, and unsaturated fatty acids. The natural antioxidants are necessary to repair the oxidative damage as the internal defense system cannot offer complete protection versus the over-all oxidative stress that humans are exposed to. Plants are source of several phytochemicals with in vitro antioxidant activity-a reason to be promising anti-oxidative stress agents [25]. Greater production of free radicals, in particular ROS, might be 
caused by extreme dexamethasone amounts. Free radicals increase mitochondrial permeability, mitochondrial dysfunction, and apoptosis in cells and decreased cellular energy production $[19,39]$.

\section{Conclusion}

Overall, DEX-induced hepatotoxic effect appeared either by liver enzyme activity elevation or by liver homogenate antioxidant activity reduction in addition to liver histological perturbations. Although, thyme extract restored these effects, applying thyme as a medicinal plant requires formerly attention, and additional studies about thyme assess safety as well as benefits.

\section{Abbreviations}

DXM: Dexamethasone; GCs: Glucocorticosteroids; CCl4: Carbon tetrachloride; ROS: Reactive oxygen species; TAE: Thyme aqueous extract; G: Group; ALT: Alanine aminotransferase; AST: Aspartate aminotransferase; ALP: Alkaline phosphatase; LDH: Lactate dehydrogenase; GSH: Glutathione; LP: Lipid peroxidation; GSP: Glutathione peroxidase; GST: Glutathione S-transferase; GSR: Glutathione reductase; CAT: Catalase; H\&E: Hematoxylin and eosin; ANOVA: One-way analysis of variance; DNA: Deoxyribonucleic acid; SOD: Superoxide dismutase; CV: Central vein; h: Hepatic cords; $\mathrm{d}$ : Degenerative changes; $\mathrm{V}$ : Vacuolation

\section{Acknowledgements}

Not applicable.

\section{Authors' contributions}

HAS performed the literature search, data acquisition, statistical analysis, and manuscript preparation and editing. WH conceived the concept and design. HAS and WH defined the intellectual content and carried out the experimental studies. HAS, WH, and $\mathrm{KH}$ carried out the data analysis and reviewed the manuscript. All authors read and approved the final manuscript.

\section{Funding}

This research did not receive any specific grant from funding agencies in the public, commercial, or not-for-profit sectors.

\section{Availability of data and materials}

All data generated or analyzed during this study are included in this published article (and its supplementary information files).

\section{Ethics approval and consent to participate}

All experiments were carried out according to recommendations of the ethical conditions approved by the Ethics Committee of Ophthalmology Research Center, Giza, Egypt, of Experimental Animals, which conformed to the international ethics for handling and care of experimental animals according to the [12].

\section{Consent for publication}

Not applicable.

\section{Competing interests}

The authors declare that they have no competing interests.

\section{Author details}

${ }^{1}$ Medical Physiology Department, Medical Research Branch, The National Research Centre, Dokki Cairo, Egypt. ${ }^{2}$ Faculty of Science, Biochemistry Division, Chemistry Department, Beni-suef University, Beni-Suef, Egypt. ${ }^{3}$ Faculty of Postgraduate Studies for Advanced Sciences, Biotechnology Department, Beni-Suef University, Beni-Suef, Egypt. ${ }^{4}$ Department of Biochemistry, Faculty of Veterinary Medicine, Beni-suef University, Beni-Suef, Egypt.
Received: 5 July 2019 Accepted: 5 November 2019

Published online: 17 December 2019

\section{References}

1. Abdel-Aziem SH, Hassan AM, El-Denshary ES, Hamzawy MA, Mannaa FA, Abdel-Wahhab MA (2014) Ameliorative effects of thyme and calendula extracts alone or in combination against aflatoxins-induced oxidative stress and genotoxicity in rat liver. Cytotech. 66:457-470

2. Abdelhalim MA, Jarrar BM (2011) Gold nanoparticles induced cloudy swelling to hydropic degeneration, cytoplasmic hyaline vacuolation, polymorphism, binucleation, karyopyknosis, karyolysis, karyorrhexis and necrosis in the liver. Lipids Health Dis. 22:166-170

3. Aebi H (1984) Catalase in vitro. Methods Enzymol 105:121-126

4. Ahsan R, Islam M, Bulbul JI, Musaddik A, Haque E (2009) Hepatoprotective activity of methanol extract of some medicinal plants against carbon tetrachloride-induced hepatotoxicity in rats. Eur J Sci Res. 37:302-310

5. Al-Badr NA (2011) Effect of thyme powder extract and oil on carbon tetrachloride-induced liver injury. J Am Sci 7:221-227

6. Apostolova N, Blas-Garcia A, Esplugues JV (2011) Mitochondria sentencing about cellular life and death: a matter of oxidative stress. Curr Pharm Des 17:4047-4060

7. Ayroldi E, Cannarile L, Migliorati G, Nocentini G, Delfino DV, Riccardi C (2012) Mechanisms of the anti-inflammatory effects of glucocorticoids: genomic and nongenomic interference with MAPK signaling pathways. FASEB J. 26:4805-4820

8. Banchroft JD, Stevens A, Turner DR (1996) Theory and Practic of Histologixal Techniques, 4th edn. Churchil Livingstone, New York, London, San Francisco, Tokyo

9. Bastway M, Hasona N, Selemain H (2008) Protective effects of extract from dates (Phoenix dactylifera L.) and ascorbic acid on thioacetamide-induced hepatotoxicity in rats. Iran J. Pharm. Res. 7(3):193-201

10. Beutler E, Duron O, Kelly BM (1963) Improved method for the determination of blood glutathione. J Lab Clin Med. 61:882-888

11. Buhl SN, Jackson KY (1978) Optimal conditions and comparison of lactate dehydrogenase catalysis of the lactate-to-pyruvate and pyruvateto-lactate reactions in human serum at 25, 30, and 37 degrees C. Clin Chem. 24:828-831

12. Canadian Council on Animal Care "CCAC" 1993. Guide to the care and use of experimental animals, Ottawa Ontario Canada 1-298

13. Caprioli G, Maggi F, Bendif H, Miara MD, Cinque B, Lizzi AR, Fabrizia Brisdelli F, Celenza G (2018) Thymus lanceolatus ethanolic extract protects human cells from t-BHP induced oxidative damage. Food Funct. 9:3665-3672

14. Chandra K, Salman AS, Mohd A, Sweety R, Ali KN (2015) Protection against FCA induced oxidative stress induced DNA damage as a model of arthritis and in vitro anti-arthritic potential of Costus speciosus Rhizome extract. Int J Pharmacognosy Phytochem Res. 7:383-389

15. Coutinho AE, Chapman KE (2011) The anti-inflammatory and immunosuppressive effects of glucocorticoids, recent developments and mechanistic insights. Mol Cell Endocrinol. 335:2-13

16. Eaton D, Bammler T (1999) Concise review of the glutathione S-transferases and their significance to toxicology. Toxicol Sci. 49:156-164

17. El-Kader MAA, Mohamed NZ (2012) Evaluation of protective and antioxidant activity of thyme (Thymus vulgaris) extract on paracetamol-induced toxicity in rats. Aust J Basic Appl Sci 6:467-474

18. Feng R, Feng L, Yuan Z, Wang D, Wang F, Tan B et al (2013) Icariin protects against glucocorticoid-induced osteoporosis in vitro and prevents glucocorticoid-induced osteocyte apoptosis in vivo. Cell Biochem. Biophys. 67:189-197

19. Feng YL, Tang XL (2014) Effect of glucocorticoid-induced oxidative stress on the expression of Cbfa1. Chem. Biol. Interact. 207:26-31

20. Goldberg DM, Spooner RJ (1983) Assay of glutathione reductase. In: Bergmaye HU (ed) Methods in Enzymology. Academic, New York, pp 258-265

21. Grespan R, Aguiar RP, Giubilei FN, Fuso RR, Damião MJ, Silva EL et al (2014) Hepatoprotective effect of pretreatment with Thymus vulgaris essential oil in experimental model of acetaminophen-induced injury. Evid Based Complement Alternat Med. 95:36-41

22. Habig WH, Pabst MJ, Jakoby WB (1974) Glutathione S-transferases. The first enzymatic step in mercapturic acid formation. J Biol Chem. 249: 7130-7139 
23. Hasona N, Morsi A (2018) Grape seed extract alleviates dexamethasoneinduced hyperlipidemia, lipid peroxidation, and hematological alteration in rats. Ind. J. Clin. Biochem. 34(2):213-218

24. Hasona NA, Ahmed MQ, Alghassab TA, Alghassab MA, Alghabban AA (2017) Ameliorative properties of Iranian Trigonella foenum-graecum L. seeds and Punica granatum L. peel extracts in streptozotocininduced experimental diabetic guinea pigs. Asian Pac J Trop Biomed. 7(3):234-239

25. luchi TM, Akaike T, Mitsui Y, Ohshima Y, Shintani H, Azuma, et al. (2003). Glucocorticoid excess induces superoxide production in vascular endothelial cells and elicits vascular endothelial dysfunction. Circ Res. 92:81-87

26. Kamanli A, Naziroglu M, Aydilek N, Hacievliyagil G (2004) Plasma lipid peroxidation and antioxidant levels in patients with rheumatoid arthritis. Cell Biochem Funct. 22:53-57

27. Kimura M, Moteki H, Ogihara M (2011) Inhibitory effects of dexamethasone on hepatocyte growth factor-induced DNA synthesis and proliferation in primary cultures of adult rat hepatocytes. J Pharmacol Sci 115:390-398

28. Lu SC (2008) Antioxidants in the treatment of chronic liver diseases: why is the efficacy evidence so weak in humans? Hepatology. 48:1359-1361

29. Luskin AT, Antonova EN, Broder MS, Chang EY, Omachi TA, Ledford DK (2016) Health care resource use and costs associated with possible side effects of high oral corticosteroid use in asthma: a claims-based analysis. Clinicoecon Outcomes Res. 8:641-648

30. Miguel MG (2010) Review: Antioxidant activity of medicinal and aromatic plants. Rev Flavour Fragrance J. 25:291-312

31. Mikiewicz M, Otrocka-Domagała I, Paździor-Czapula K, Rotkiewicz T (2017) Influence of long-term, high-dose dexamethasone administration on proliferation and apoptosis in porcine hepatocytes. Res Vet Sci. 112:141-148

32. Ohkawa H, Ohishi N, Yagi K (1979) Assay for lipid peroxides in animal tissues by thiobarbituric acid reaction. Anal. Biochem. 95:351-358

33. Pagana KD, Pagana TJ (2002) Mosby's manual of diagnostic and laboratory tests, 2nd edn. Mosby, St Louis, Missouri USA, pp 1-44

34. Paglia DE, Valentine WN (1967) Studies on the quantitative and qualitative characterization of erythrocyte glutathione peroxidase. J Lab Clin Med 70: 158-169

35. Reitman A, Frankel SA (1957) Colorimetric method for the determination serum glutamic oxaloacetic and glutamic pyruvic transaminases. Am J Clin Pathol. 28:56-63

36. Rosalki SB, Foo AY, Burlina A, Prellwitz W, Stieber P, Neumeier D et al (1993) Multicenter evaluation of Iso-ALP test kit for measurement of bone alkaline phosphatase activity in serum and plasma. Clin. Chem. 39:648-652

37. Safaei N, Shomali T, Taherianfard M (2012) Niacin ameliorates lipid disturbances due to glucocorticoid administration in rats. Iran J Basic Med Sci. 15(4):997-1002

38. Saha S, Mukhopadhyay MK, Ghosh PD, Nath D (2012) Effect of methanolic leaf extract of Ocimum basilicum L. on benzene-induced hematotoxicity in mice. Evid Based Complement Alternat Med. 17:63-85

39. Sato H, Takahashi T, Sumitani K, Takatsu H, Urano S (2010) Glucocorticoid generates ROS to induce oxidative injury in the hippocampus, leading to impairment of cognitive function of rats. J. Clin. Biochem. Nutr. 47:224-232

40. Shati AA, Elsaid FG (2009) Effects of water extracts of thyme (Thymus vulgaris) and ginger (Zingiber officinale Roscoe) on alcohol abuse. Food Chem Toxicol. 47:1945-1949

41. Sinha K, Das J, Pal PB, Sil PC (2013) Oxidative stress: the mitochondriadependent and mitochondria-independent pathways of apoptosis. Arch. Toxicol. 87:1157-1180

42. Subramaniam S, Khan HBH, Elumalai N, Lakshmi SYS (2015) Hepatoprotective effect of ethanolic extract of whole plant of Andrographis paniculata against CCl4-induced hepatotoxicity in rats. Comp Clin Pathol. 1-7

43. Tabari MA, Youssefim MR, Maggi F, Benelli G (2017) Toxic and repellent activity of selected monoterpenoids (thymol, carvacrol and linalool) against the castor bean tick, Ixodes ricinus (Acari: Ixodidae) Vet. Parasitol. 245:86-91

44. Vegiopoulos A, Herzig S (2007) Glucocorticoids, metabolism and metabolic diseases. Mol Cell Endocrinol. 275:43-61

45. Wang B, Van Veldhoven PP, Brees C, Rubio N, Nordgren M, Apanasets O et al (2013) Mitochondria are targets for peroxisome-derived oxidative stress in cultured mammalian cells. Free Radic. Biol Med. 65:882-894

46. Wei L, MacDonald TM, Walker BR (2004) Taking glucocorticoids by prescription is associated with subsequent cardiovascular disease. Ann Intern Med. 141:764-770

47. Zanchi NE, Guimarães-Ferreira L, de Siqueira-Filho MA, Felitti V, Nicastro $H$, Bueno C et al (2012) Dose and latency effects of leucine supplementation in modulating glucose homeostasis: Opposite effects in healthy and glucocorticoid-induced insulin-resistance states. Nutrients. 4:1851-1867

48. Zhang W, Wang SH (2001) Antioxidant activity compounds in selected herbs. Agrie Food Chem. 49:5165-5170

49. Zhu R, Wang Y, Zhang L, Guo Q (2012) Oxidative stress and liver disease. Hepatol Res. 42:741-749

\section{Publisher's Note}

Springer Nature remains neutral with regard to jurisdictional claims in published maps and institutional affiliations.

\section{Submit your manuscript to a SpringerOpen ${ }^{\circ}$ journal and benefit from:}

- Convenient online submission

- Rigorous peer review

- Open access: articles freely available online

- High visibility within the field

- Retaining the copyright to your article

Submit your next manuscript at $>$ springeropen.com 